УДК 821

\title{
С.Н. Любарец
}

\section{ПСЕВДОДОКУМЕНТАЛЬНЫЙ ДИСКУРС В РОМАНЕ Ф. БЕГБЕДЕРА «ИДЕАЛЬ»}

Художественная структура романа Бегбедера «Идеаль» включает в себя как документальное начало, так и ряд псевдодокументальных фрагментов: письма, свидетельские показания, выдержки из протоколов допроса, официальные сообщения, материалы блога главной героини и др. Подобный принцип организации текста, сочетающий документальное и художественное, способствует выявлению авторской интенции и открывает возможности для более глубокого прочтения произведения в целом. Читатель активно вовлекается не только в социокультурный контекст современной России, но и в сложные процессы глобализации человечества.

Ключевые слова: документальный, псевдодокументальный дискурс, авторская интенция, социокультурный контекст, постмодернистское повествование.

DOI: $10.35634 / 2412-9534-2021-31-2-374-381$

Сегодня, в XXI в., феномен документальности в художественной литературе имеет самостоятельное эстетическое значение. Исследователи полагают, что начало этой тенденции положил XX в.: «Причин, вызвавших столь мощный всплеск в развитии документального начала в литературе, много: и поляризация в XX в. вымысла и правды, зачастую столь мирно неразлучных в предыдущие эпохи; и интенсивность современной жизни, и способность факта (документа) дать выход «таланту самой жизни» и т. д. и т. П.» [5]. П.В. Палиевский, определяя роль и функции документа в художественном тексте, пишет: «Интересно, что документ начал сообщать правду в подробностях, которые в литературе так или иначе не были приняты. Он взял эти права, подобно скульптуре, про которую Лессинг говорил, что она может показывать то, что не разрешается слову, только, конечно, шире, потому что он стал открывать все неумышленно. Этим он тоже раздвинул привычные возможности» [8].

Масштабно заявив о себе в XX в., феномен документальности продолжает успешно функционировать в современном литературном пространстве, проявляя себя в различных модификациях: «...всюду документ принялся с невероятной настойчивостью пробивать себе путь и всюду победил» [6, с. 13]. Зачастую в художественной прозе документальность как исторический факт, как свидетельство подлинности событий и судеб подменяется или дополняется псевдодокументальным материалом, стремящимся в свою очередь создать иллюзию достоверности. В настоящее время эта «особая форма литературной мистификации» настойчиво завоевывает свое место в мире художественной литературы [6, с. 41].

Использование документа или его фикции в художественном тексте интерпретируется в большинстве случаев как литературный прием, полноценное средство поэтики, способное реализовать самые серьезные авторские замыслы. Говоря о жанровой сфере документального текста, С.Н. Ивашкин пишет: «В художественном мире они копируются, имитируются, пересказываются, упоминаются, играя важную роль в социальнокультурной, речевой характеристике персонажей, в сюжетнокомпозиционном целом литературного текста» [3]. Исследователи совершенно справедливо утверждают, что дело не только в «технических» возможностях факта (документа) в организации художественного целого, но и в его способности реализовывать наиболее важные и трудные задачи, носящие «всеобщий (всемирный) характер» [5]. Не вызывает сомнения, что, соединение двух начал - художественного и документального в различных его проявлениях - позволяет значительно расширить возможности и границы текста и стимулирует автора в его стремлении подняться до глобальных проблем человека и времени.

В повествовательной структуре романа известного современного французского писателя и публициста Ф. Бегбедера «Идеаль» (2007), наряду с вымышленным сюжетом, широко используются подлинные факты, называются реальные имена и события. Кроме того, автор намеренно вводит псевдодокументальные материалы, которые не только дополняют общий событийный контекст, но и выполняют различные функции художественно-эстетической направленности. Предполагается, что сочетание художественного и документального / псевдодокументального начал выступает как особый принцип организации текста и способствует выявлению авторской интенции, что в свою очередь открывает возможности для более глубокого прочтения произведения. 
Как типичное постмодернистское повествование, роман Бегбедера наделен специфической жанровой природой, синтезировавшей в себе свойства травелога, компоненты исповедального текста, черты автобиографии, элементы документальности и др. Такое сложное жанровое решение дополняется своеобразным сюжетно-композиционным построением и обогащается наличием двух четко различимых уровней: внешнего - язвительно-ироничного, во многом эпатажного и внутреннего - тяготеющего к рефлексии, к попытке понять современного человека, осмыслить глубинную суть геополитических и исторических процессов, происходящих в меняющемся мире. Полифоничное художественное пространство романа оказывается открытым для взаимодействия различных видов дискурса. Исследователи творчества Бегбедера традиционно выделяют дискурс русской литературы, явно просматривающийся на страницах романа «Идеаль», в настоящей статье предпринята попытка изучить своеобразие псевдодокументального дискурса. Авторская нарративная стратегия в романе отличается богатым набором постмодернистских техник и включает в себя игровое начало - игру смыслами, словами, намеками и др. Игровое пространство романа «Идеаль» конструируется, в частности, и посредством внедрения вымышленных документов, которые, как и настоящие, должны стать одним из голосов изображаемой эпохи и удовлетворять определенные ожидания читателя.

Содержание романа «Идеаль» построено на материале жизни России начала XXI в., посткоммунистической страны, приобщившейся к достижениям европейской цивилизации и как следствие оторвавшейся от своих корней и утратившей национальную самобытность. Несмотря на то, что местом действия в романе является Россия, обличительный пафос текста направлен не только на русскую действительность, автор критикует ситуацию в мире в целом. В частности, объектом осмысления становятся нравы рекламно-модельного бизнеса, олицетворяющие общественные пороки современности и выступающие по сути как характерные приметы нашего времени. Главный герой рекламный агент Октав Паранго, «французский скаут, застрявший в стране, которая равняется тридцати Франциям» (под этим именем он уже фигурировал в романе Бегбедера «99 франков»), приезжает в Россию в поисках модели для рекламы мировой косметической корпорации под названием «Идеаль». Перевод названия романа на русский язык не соответствует оригиналу - «Au secours pardon» (дословный перевод - «На помощь простите» - является фрагментом католической молитвы). Вариант русского перевода «Идеаль» согласован с автором и, вполне очевидно, сознательно направлен на ассоциацию с популярным в России косметическим продуктом.

Сюжет романа погружает читателя в широкий социокультурный контекст современной России, дав возможность герою совершить своего рода путешествие, посетить различные русские города, познакомиться с традициями и нравами русских людей, окунуться в политические и культурные реалии страны. В то же время автор погружает нас в историческое прошлое - советское время, воссоздавая картины быта, намекая на особенности общественно-политической и культурной жизни советских людей. Многочисленные исторические аллюзии отсылают и к другим эпохам, «формируя типологические связи, создавая своеобразную перекличку времен» [7]. Характерно, что Россия рассматривается автором как часть мировой цивилизации, вписывается в сложные процессы глобализации. Художественное пространство романа, таким образом, выступает как характеристика эпохи в целом, эпохи, которую герой романа называет «нашим бесхребетным временем» [2]. Писатель рефлексирует о судьбах всего человечества, перешагнувшего рубеж второго тысячелетия и погрузившегося в мир хаоса, виртуальной действительности, мир, управляемый Интернетом, гаджетами, соцсетями и др. Россия, с его точки зрения, отказавшись от национальной самобытности, движется, как и весь мир, ко всеобщему духовному оскудению, всеобщей нравственной деградации. Он пишет: «Мы вступили в эру сексапильной бесчеловечности» [2]. Устами героя автор констатирует, что в современном мире «эгоцентризм стал доминирующей идеологией», что гедонистическая мораль поработила человека, что тотальное одиночество стало неизбежным, несмотря на наличие самых передовых технических возможностей для коммуникации, которые на самом деле оказываются фикцией, только создающей «иллюзию связи с вселенной» [2].

Стереотипные представления о России, сложившиеся в процессе многовекового взаимодействия с Западом, в том числе и с Францией, не могли не оказать влияния на писателя. Поэтому историческое прошлое и события сегодняшней России интерпретируются писателем через призму привычных штампов, устойчивых клише, давно ставших частью европейского культурного сознания. Тем не менее, ему удается в некоторой степени модернизировать традиционные представления о России, обогатить их современным контентом и тем самым обеспечить качественно новый уровень осмысле- 
ния России и русских. Надо отдать должное и следующему факту: писатель владеет достаточно глубокими познаниями в области русской истории, культуры и литературы, имеет весьма объективные представления о современных нравах русского социума, разбирается в историко-политических коллизиях. Он часто посещает Россию, лично знаком со многими русскими писателями, политиками, олигархами, деятелями культуры и т. п. Это позволяет автору вписать в текст богатый фактический материал, формирующий весьма серьезный документальный пласт. Литературовед О. Калашникова пишет: «Знаки России удивительно точны и могут служить своеобразным путеводителем не только по туристической карте для иностранного путешественника, но и реперными точками для последующих поколений историков» [4]. Установкой на документальность можно считать тот факт, что писатель называет в том или ином контексте огромное количество конкретных имен реальных людей из разных сфер жизни, Например, кратко анализируется карьерный путь представительниц модельного бизнеса - Клаудии Шиффер, Натальи Водяновой, Кейт Мосс. Упоминаются известные исторические личности и комментируется их влияние на судьбы России: Иван Грозный, Петр Первый, Екатерина Великая, Сталин, Горбачев, Путин и др. Автор многократно апеллирует к именам классиков русской и зарубежной литературы, не забывая и представителей современной литературы: Пелевина, Геласимова, Сорокина и др.

Привлечение документальных элементов и сохранение исторической фактографии наблюдаются при создании образов центральных русских городов: Москвы, Н. Новгорода и Санкт-Петербурга. Писатель делает их узнаваемыми, пытается сохранить их историческую идентичность, хотя, безусловно, они заряжены авторским видением. Москву он называет «Городом Обманутых Надежд», читателю предлагается обозреть общеизвестные в стране и мире московские достопримечательности: Храм Христа Спасителя, новодел с его «невсамделишным убранством», Дом на набережной, Мовзолей, Лубянка, памятник Карлу Марксу, роскошные бутики ГУМа, модные ночные кафе и клубы и др. Автор с иронией отмечает, что многие из них маркированы признаками «европеизации»; теперь уже не партийными лозунгами, как в советское время, а рекламными щитами пестрят улицы и площади столицы. Например, прямо напротив мавзолея Ленина читаем рекламный слоган «От Правды до Прады один шаг»[2]. Полным туристическим набором штампов представлено пространство СанктПетербурга - культурной столицы России: Летний сад, белые ночи, каналы, разводные мосты, 900 голодных дней блокады, наводнения, Петергоф и его дворцы, Академия художеств, театры и балерины знаменитой Мариинки, музеи-квартиры Достоевского и Пушкина, дом, где жил Владимир Набоков, Черная речка, место смертельного ранения первого поэта России и т. п. Не менее четко и точно обозначенным предстает облик приволжского города - Нижнего Новгорода, на привокзальной площади которого рядом с уцелевшим памятником Ленина удобно расположился фастфудный ресторан «Макдональдс». Авторская ирония отступает на второй план, когда герой вполне искренне любуется золочеными куполами многочисленных православных храмов, украшающих урбанистическое пространство столичных городов и берега великой русской реки Волги.

Таким образом, читатель погружается в реалии современной России, не сомневаясь в их подлинности и в то же время улавливая нескрываемую иронию по поводу той зачастую неуместной модернизации, которой подвергаются памятники русской истории, архитектуры и культуры: «Когда я мчался по Театральному проезду, там уныло толпились бедняги, не попавшие в клуб «Osen», а напротив возвышалась статуя Ивана Федорова, русского Гуттенберга, оглушенного R\&B и зажатого между магазином «Бентли», дистрибьютором «Феррари» и ювелирным бутиком «Булгари». Человек, давший в XVI веке старт русской литературе, теперь взят в тиски блядским клубом и шикарными гаражами и обязан слушать целый день напролет «Jenny from the Block» - незавидная судьба!» [2].

Целый ряд текстовых вставок псевдодокументального характера, который включает в себя повествовательная структура романа, формируют также свой особый смысловой континуум, связанный и с сюжетной линией, и с его внутренним смыслом. Речь идет о материалах расследования компетентными органами совершённого в Москве главным героем Октавом Паранга преступления, признанного официальными властями террористическим актом, - взрыва собора Христа Спасителя. Большинство из представленных в тексте деловых бумаг имеет отношение к правоохранительной сфере: это прежде всего свидетельские показания и выдержки из протоколов допросов подозреваемых. В романе фигурируют и привлеченные к расследованию фрагменты писем (например, письма бывшей супруги подозреваемого и его матери), направленных следователям Управления по борьбе с организованной преступностью. К делу приобщаются и материалы более современного характера - 
на электронных носителях: это отрывки из блога героини Елены Дойчевой, электронная версия дневника. Кроме того, имеется официальное сообщение СМИ в виде отчета МЧС о теракте. В данном случае читателю предлагаются не подлинные документы, а стилизованный под документ авторский вымысел. Тем не менее, очевидна установка писателя на воспроизведение через фикцию документа жизненных реалий. Автор предпринимает игру с читателем, намеренно пародируя и саму ситуацию с документами, и формальные признаки документальных материалов.

Группа представленных в тексте документальных письменных высказываний обладает смысловым единством как на формально-содержательном, так и на идейном, внутреннем уровне. Писатель сознательно фокусирует внимание читателя на документальном пласте, выделяя его курсивным шрифтом (кроме блога героини). Понятно, что «игра различными шрифтами позволяет обозначить и разграничить разное письмо-дискурс» [4]. Более того, в скобках или просто жирным шрифтом, в конце документа, номинируется жанр каждого конкретного вкрапления: показания, протокол, письмо, страницы блога и др. При этом даты не указываются, имена следователей или составителей протоколов не называются. Так, например, представлены отдельные свидетельские показания, зарегистрированные в Главном следственном управлении ГУВД Москвы: «Не знаю, чем вам могут помочь мои показания по этому делу. Я хотела бы быть вам полезной, я пытаюсь честно ответить на все ваши вопросы, но это не так просто, боюсь, что поезд ушел и копание в нашей супружеской жизни, закончившейся полным провалом, вряд ли прольет свет на тайны международного терроризма! <..> Нет, я не знаю, были ли у него сообщники, после развода мы практически не общались. Полагаю, что, с технической точки зрения, организовать такую операчию в одиночку довольно сложно. Нет, он мне никогда не рассказывал ни о своих знакомствах в среде российских предпринимателей, ни о чеченских сепаратистах, прошу меня не впутывать в эту историю и не упоминать моего имени, мне еще жить не надоело! <... С Слава богу, этот псих не свел меня в могилу. Извините, я не имею в виду то, что произошло... я неловко выразилась. Мне повезло больше других. Я знала, что он поселился в Москве видно, для того, чтобы трахать тамошних шлюх, но мне бы никогда и в голову не пришло, что он может встать на путь насилия. Как все садисты, он был очень мягким человеком и всегда кичился своей трусостью. Я не думала, что он способен причинить зло кому-нибудь, кроме меня. Я глубоко скорблю о многочисленных жертвах и чувствую свою ответственность за случившееся, если б $я$ только знала, что он может решиться на такое... Октав все время, повторял мне, что сошел с ума, но я ему не верила. Я не понимала, как кто-то, кого не существует, может быть сумасшедшим. (Выдержки из письма, направленного бывшей супругой подозреваемого следователям Управления по борьбе с организованной преступностью. Подшито к делу о храме Христа Спасителя.)».

Еще один пример - выдержка из свидетельского показания: «Кто вам дал мой телефон? A, тот франиуз, который принял меня за белоруску, - так я развела его как лоха, черт меня дернул оставить ему свои координаты. Он всю ночь напролет выпрашивал у меня мой номер телефона! Он искал наркотики, уверял меня, что завязал, но почему-то только о них и говорил, как все наркоманы в ломке. Сказал, что с кокаином вечно одно и то же - либо его нюхаешь слишком много, либо слишком мало. Во урод! Но у меня, есть принцип: я своего телефона никому не даю, а то потом неприятностей не оберешься, и ваш звонок - лучшее тому доказательство! Татьяна С., студентка, Нижний Новгород» [2].

Внедрение в художественный текст так называемых документов позволяет автору, с одной стороны, убедить читателя в объективности рассказа, то есть придать правдоподобие описываемым событиям. С другой стороны, писатель не скрывает своего намерения оперировать не подлинником, а только создать иллюзию настоящего документа. Он осознанно нарушает один из важнейших принципов документальности - направленность на достоверность, поэтому не имитирует документальное письмо, не воспроизводит формальные атрибуты документа, а, напротив, создает свободные от бюрократических штампов тексты, напоминающие по стилю «исповедальный» рассказ главного героя. Читатель легко распознает в псевдодокументах особенности авторской манеры письма, готов оценить авторскую иронию, являющуюся доминирующим модусом всего повествования. Писатель создает такую игровую ситуацию, при которой он не манипулирует сознанием читателя и не обманывает его ожидания. Принцип игры позволяет принять ложный посыл документальности - вымышленные протоколы допросов, свидетельские показания и пр. - как правду, а не ее иллюзию или фикцию. Читательское сознание принимает постмодернистскую игровую тактику писателя и подключается к игре. 
Важно обратить внимание на то, что, вместо официально-делового стиля, призванного запротоколировать факты и события, данные свидетелей, предлагается самовыражение персонажей, которые во многом имитируют авторский стиль письма. Дискурсивная практика, когда писатель делегирует свойства своей речи другим персонажам, призвана продемонстрировать их духовное родство, близость во взглядах на мир. Экзистенциальные мотивы (одиночество, странничество, эскапизм, наркотики и алкоголь, эгоистическая разобщенность людей) как примета времени звучат и в псевдоисповедальных признаниях героя Октава Праранго, и в показаниях свидетелей. Так, герой, излагая свои мысли примитивным языком рекламного слогана, говорит о вещах серьезных, звучащих как философские размышления: «Человек мчится стремглав в мир удовольствий»; «индустрия гедонизма предлагает пугающее количество развлечений..»; «смириться с ничтожностью человека - вот начало мудрости» и т. п. [2]. В признаниях свидетелей также часто слышим нотки разочарования, неудовлетворенности, нежелания жить. Лена Дойчева в своем блоге говорит, что ее неоднократно посещали мысли о самоубийстве. Вымышленные документальные материалы - в данном случае письменные показания - позволяют автору подтвердить актуальность и своевременность разговора о вечных, экзистенциальных темах - о проблемах человеческой цивилизации, о взаимоотношениях людей, о жизни и смерти, о познании самого себя. Повторяя авторские оценки современного мира, герои романа в своих свидетельских показаниях как будто соотносят личный социальный и эмоциональный опыт с опытом других людей. Исследователь С.В. Мещеряков справедливо отмечает, что «постоянная смена позиции объекта речи на уровне наррации становится значимым фактором выявления авторских представлений о трагической противоречивости современного человека» [7]. Идея безысходности и бесцельности существования современного человечества пронизывает весь текст, но не создает ощущения абсолютного пессимизма, поскольку авторская ирония нивелирует драматизм бытия, а бесконечные поиски героем романтической мечты - настоящей любви дают читателю надежду на более гармоничное будущее. Тем не менее, экзистенциальные настроения становятся лейтмотивом книги в целом и выполняют функцию подтекста.

В то же время нельзя не заметить, что материалы псевдодокументов выступают как важное средство характеристики героев, используются автором для выявления и анализа различных типов сознания. Письменные показания и материалы допросов героев становятся своего рода субъектами речи, а значит, носителями индивидуальных ценностей. Для обозначения конкретного психотипа личности используются приемы риторики, речевая характеристика маркирует образ персонажа, делает его узнаваемым, выстраивая определенный ассоциативный ряд. Так, героиня романа Елена Дойчева, первая настоящая любовь Октава Паранго, воспринимается поначалу как «тургеневская девушка» - признанный в культурном сознании людей эталон непорочности и чистоты. Влюбленный герой называет ее «сновидением, от которого не хотелось проснуться», идеалом «божественной красоты, которая не имеет изъянов» [2]. Однако ее дневник опровергает это ошибочное впечатление, раскрывает истинную суть натуры девушки. Перед нами циничное, лицемерное и весьма развращенное юное создание, поставившее перед собой цель любой ценой вырваться из бедной и скучной жизни российской провинции: «В маминой тумбочке нашла вибратор в форме помады. У меня, по-моему, нервное истощение. Я им развлекалась весь день, устала до ужаса, это какой-то карманный наркотик, задарма и до отвала. Мне на ум приходят всякие гадости о том, что с ним можно придумать, не буду вам о них рассказывать, стыдно. Я открыла для себя оргазм в одиннадцать лет, потерев ляжки друг о друга. Но тут, тут... вот адская машинка... Я вышла на кухню вся красная и потная, чтобы приготовить ужин, - просто пай-девочка с ангельским личиком. Я помолилась перед едой - на всякий случай» [2].

Еще одним ярким примером могут служить выдержки из показаний олигарха Сергея Орлова, носящего в тексте романа кличку Идиот - понятная аллюзия на Достоевского, однако с ироническим подтекстом и противоположной коннотацией. В финале романа именно он становится президентом России. Фрагмент из письменных показаний Сергея Орлова воспринимается как средство речевой характеристики, дополняющее образ отрицательного персонажа. Избитые фразы, ни к чему не обязывающие пустые слова, надоевшие речевые клише, которые использует этот «слуга режима» «при даче показаний под присягой», как иронично замечает автор, пародируют речь официальных представителей российской власти: «Мне нечего добавить относительно этого дела, которое глубоко возмущает и огорчает меня, как и всех жителей нашего города, в частности православную общину, к которой я имею честь принадлежать, а также мою семью и моих близких, всю глубину скорби которых вы можете себе представить. Напоминаю, что, несмотря на свое еврейское происхождение, я был 
одним из основателей в 1994 г. комитета спонсоров, который положил начало финансированию строительства храма Христа Спасителя. Позвольте мне выразить солидарность и принести соболезнования всем семьям, потерявшим близких вследствие этого чудовищного, бесчеловечного и богохульственного деяния. Я присоединяюсь к молитвам всей «Единой России» и хочу засвидетельствовать свою неизменную поддержку президенту Путину в его борьбе за правое дело. В один прекрасный день нам придется задуматься о полной и окончательной зачистке святой русской земли, а также покарать всех тех, кто ставит под сомнение национальное величие России и плюет в душу нашей великой державы. Эту борьбу ведет наш президент и будет вести его преемник - тот, кого выберет народ. Пока российскому начиональному единству угрожает террористическая опасность, во главе демократии должны стоять люди с железной волей» [2].

Одновременно автор использует документальные пассажи в свойственной им функции - как некий источник достоверности, излагающий подлинные факты, возлагающий на себя миссию воспроизведения объективных реалий, которые вполне могли иметь место в России. Например, в придуманных автором протоколах допросов изображается использование пыток и насилия, хотя, как известно, в официальных документах не принято фиксировать случаи применения жестокости по отношению к обвиняемым или свидетелям. Тем более, не заведено отмечать в протоколах их эмоциональную реакцию на насильственные действия. Бегбедер намерено вставляет в протоколы допросов сцены пыток, тем самым он подает события в необходимой ему трактовке и формирует определенное восприятие этих фактов читателем. Он демонстрирует свое отношение к происходящему, создавая пародийно-ироничный подтекст, который несколько смягчает принятие агрессии в действиях сотрудников органов безопасности. Не секрет, что российские органы ФСБ (КГБ, НКВД в советский период истории) демонизируются на Западе, поэтому автор умело использует стратегию, готовящую читателя к восприятию игрового сюжета, то есть не обманывает ожидание читателя, а, напротив, убеждает в вероятности сюжета, в реальности подобных фактов. Например, выдержка из протокола допроса чеченки Елены Дойчевой, произведенного сотрудником УРПО в помещении ФСБ: «Я не знаю, почему у пего вдруг крышу снесло... Это ужасно, ужасно... А с виду умный человек, и руки у него были такие красивые, не понимаю ... ... Ну что я могла поделать? Как мне было догадаться, что он на такое пойдет? Теперь моя карьера накрылась, в этой сфере я погорела, что со мной будет? Я вообще к этому кошмару не имею отношения. Мне вечно не везет. .. ... Пожалуйста, прошу вас, развяжите меня, будьте добры, дайте мне стакан воды, без полония., если можно, я уже два дня не пила, не ела, верните мою одежду, спасибо, нет, не надо, не бейте меня больше шлангом, я... я буду с вами сотрудничать, умоляю, стакан воды, у меня болят запястья и живот, и колики уже начинаются, не хочу, чтобы тот человек вернулся, умоляю, он так больно хватал меня за грудь электрическими щипиали... Из протокола допроса Лены Дойчевой» [2]. С одной стороны, писатель констатирует непреложный факт: подобные случаи имеют место в нашей судебной практике, но, с другой - он создает псевдопротокол, в котором подвергает иронической интерпретации не сам факт применения насилия, а документ, так называемый протокол, в котором обнародованы ситуации, когда применяются различные средства и инструменты насильственного добывания показаний от подозреваемых или свидетелей. Читатель, понимая ситуацию, подхватывает игру смыслами, предложенную автором. Становится понятно: использование псевдодокумента выступает в романе как своеобразный художественный прием, призванный выполнить и обвинительную/критическую функцию по отношению к российским или советским правоохранительным институтам, и можно предположить, выражающий одновременно неприятие автором любых форм насилия, независимо от того, в какой стране и в какое время они осуществляются.

Документальный посыл в виде фикциональных деловых бумаг позволяет автору реализовать еще одну цель: главный герой Октав Паранго получает дополнительные, более глубокие психологические характеристики, поскольку представлен самыми разными людьми, разными уровнями сознания: здесь и бывшая супруга, и мать, и возлюбленная, и случайно встреченные девушки, и коллеги по бизнесу и многие другие. Мнения многочисленных свидетелей и подозреваемых о личности героя во многом совпадают и, что самое важное, не разрушают заданный писателем в псевдоисповедальном монологе Октава Паранго образ человека экзистенциального типа, болезненно переживающего несостоятельность современного мироустройства и гедонистических устремлений человечества, человека, находящегося в состоянии тяжелого кризиса самоидентичности. Напротив, писатель убеждает читателя в правильности всех вместе взятых оценок и самооценок. 
Таким образом, можно утверждать, что автор романа «Идеаль» Бегбедер, избирав стратегию в русле традиций постмодернистского повествования, не случайно включает в его художественную структуру документальный и псевдодокументальный дискурсы. Этот особый пласт принимает участие в формировании сюжетно-композиционного корпуса сочинения, обогащает новыми нюансами созданный на страницах социокультурный контекст эпохи, служит дополнительным инструментом для характеристики героев, их психологии и поступков и т. п. Более того, он помогает реализовать метасюжет, идейный смысл которого заключается в попытке создать подлинную социальную и культурно-историческую хронику нашего времени и одновременно постулировать обличительную мысль об отсутствии в современном мире разумной логики. В атмосфере абсурда, в условиях господства «золотого тельца» и культа молодости подмена истинного ложным становится не только приметой времени, но и способом выживания. Поэтому настоящий документ и его фикция уравниваются в правах, они способны практически одинаково передавать дыхание времени и чаяния людей.

\section{СПИСОК ИСТОЧНИКОВ И ЛИТЕРАТУРЫ}

1. Beigbeder F. Au secours pardon. Paris: Gallimard, 2007. 309 p.

2. Бегбедер Ф. Идеаль [Электронный ресурс]. URL: https://www.litres.ru/frederik-begbeder/ideal/chitat-onlayn/ (дата обращения 25.02.2021).

3. Ивашкин С.Н. Поэтика документа в художественном тексте и культуре // Дергачевские чтения - 2006. Русская литература: национальное развитие и региональные особенности: материалы международной научной конференции, Екатеринбург, 5-7 октября 2006 г. Екатеринбург: Издательство Уральского университета; Изд. дом «Союз писателей», 2007. Т. 2. С. 96-98.

4. Калашникова О. Л. Литературный код романа Ф. Бегбедера «Au secours pardon» («Идеаль») [Электронный pecypc]. URL: http://www.irbis-nbuv.gov.ua/cgi-bin/irbis_nbuv/cgiirbis_64.exe?C21COM=2\&I21DBN=UJRN $\& P 21 D B N=U J R N \& I M A G E \_F I L E \_D O W N L O A D=1 \& I m a g e \_$file_name=PDF/Npkpnu_fil_2012_30_33.pdf (дата обращения 25.02.2021).

5. Литература и документ: теоретическое осмысление темы (материалы круглого стола) [Электронный ресурс]. URL: http://www.lych.ru/online/0ainmenu-65/40-s32009/365 (дата обращения 14.04.2012).

6. Местергази Е.Г. Литература нон-фикшн/non-fiction. Экспериментальная энциклопедия. Русская версия. М.: Совпадение, 2007. 325 с.

7. Мещеряков С.В. Романы Ф. Бегбедера «99 франков» и «Идеаль»: принципы художественной объективации автора [Электронный ресурс]. URL: https://www.dissercat.com/content/romany-f-begbedera-99-frankov-i-idealprintsipy-khudozhestvennoi-obektivatsii-avtora (дата обращения 25.02.2021).

8. Палиевский П.В. Документ в современной литературе [Электронный ресуpc]. URL: http://american-lit.niv.ru/ american-lit/palievskij-literatura-i-teoriya/dokument-v-sovremennoj-literature.htm (дата обращения 25.02.2021)

Поступила в редакцию 07.06.2020

Любарец Светлана Николаевна, кандидат филологических наук, доцент

кафедры теории языка, межкультурной коммуникации и зарубежной литературы

ФГБОУ ВО «Удмуртский государственный университет»

426034, Россия, г. Ижевск, ул. Университетская, 1 (корп. 2)

E-mail: lub-sv@yandex.ru

\section{S.N. Lyubarets \\ PSEUDO-DOCUMENTARY DISCOURSE IN F. BEIGBEDER'S NOVEL “AU SECOURS PARDON"}

DOI: $10.35634 / 2412-9534-2021-31-2-374-381$

The narrative structure of the novel "Au secours pardon" by F.Biegbeder includes rich documentary materials and such pseudo-documentary fragments as letters, witness testimonies, extracts from interrogation reports, official reports and materials from heroin Lena Doycheva blog. This principle of text composition opens the possibility to understand the author's intention and to extend our knowledge of the novel contents. The readers are actively drawn both into the processes of the social and cultural life of modern Russia and into the complex processes of humanity globalization.

Keywords: pseudo-documentary discourse, author's intention, social and cultural context, postmodern narration. 


\section{REFERENCES}

1. Beigbeder F. Au secours pardon. Paris: Gallimard, 2007. 309 p. (In French).

2. Begbeder F. Ideal' [Elektronnyj resurs]. URL: https://www.litres.ru/frederik-begbeder/ideal/chitat-onlayn/ (accessed 25.02.2021). (In Russian).

3. Ivashkin S.N. Poetika dokumenta $v$ hudozhestvennom tekste i kul'ture [Poetics of the document in the literary text and culture] // Dergachevskie chteniya - 2006. Russkaya literatura: nacional'noe razvitie i regional'nye osobennosti: materialy mezhdunarodnoj nauchnoj konferencii, Ekaterinburg, 5-7 oktyabrya 2006 g. Ekaterinburg: Izdatel'stvo Ural'skogo universiteta; Izdatel'skij dom «Soyuz pisatelej», 2007. T. 2. S. 96-98 [Dergachevskie chteniya - 2006. Russkaya literatura: nacional'noe razvitie i regional'nye osobennosti: materialy mezhdunarodnoj nauchnoj konferencii, Ekaterinburg, 5-7 oktyabrya 2006 g. Ekaterinburg: Izdatel'stvo Ural'skogo universiteta; Izdatel'skij dom "Soyuz pisatelej", 2007. T. 2. S. 96-98]. (In Russian).

4. Kalashnikova O.L. Literaturnyj kod romana F. Begbedera «Au secours pardon» («Ideal'») [The literary code of the novel by F. Begbeder "Ai secours pardon" ("Ideal»)]. URL: http://www.irbis-nbuv.gov.ua/cgi-bin/irbis_nbuv/ cgiirbis 64.exe?C21COM=2\&I21DBN=UJRN\&P21DBN=UJRN\&IMAGE FILE_DOWNLOAD=1\&Image file $n$ ame $=$ PDF/Npkpnu fil 2012 30 33.pdf (accessed 25.02.2021). (In Russian)

5. Literatura i dokument: teoreticheskoe osmyslenie temy (materialy kruglogo stola) [Literature and document: theoretical understanding of the topic (materials of the round table)]. URL: http://www.lych.ru/online/ 0ainmenu-65/40 s32009/365 (accessed 14.04.2012). (In Russian)

6. Mestergazi E.G. Literatura non-fikshn/non-fiction. Eksperimental'naya enciklopediya. Russkaya versiya[ Non-fiction literature. Experimental encyclopedia. Russian version]. M.: Sovpadenie, 2007. 325 p. (In Russian)

7. Meshcheryakov S.V. Romany F. Begbedera «99 frankov» i «Ideal'»: principy hudozhestvennoj ob"ektivacii avtora [F. Begbeder's novels "99 Francs" and "Ideal": the principles of artistic objectification of the author]. URL: https://www.dissercat.com/content/romany-f-begbedera-99-frankov-i-ideal-printsipy-khudozhestvennoi-obektivatsiiavtora (accessed 25.02.2021). (In Russian)

8. Palievskij P.V. Dokument v sovremennoj literature [Document in modern literature]. URL: http://americanlit.niv.ru/american-lit/palievskij-literatura-i-teoriya/dokument-v-sovremennoj-literature.htm (accessed 25.02.2021). (In Russian).

Received 07.06.2020

Lyubarets S.N., Candidate of Philology, Associate Professor at Department of Language Theory,

Crosscultural Communication, Foreign Literature

Udmurt State University

Universitetskaya st., 1/2, Izhevsk, Russia, 426034

E-mail: lub-sv@yandex.ru 